\title{
PODER E PARTICIPAÇÃO: A DELINQÜÊNCIA ACADÊMICA NA INTERPRETAÇÃO TRAGTENBERGUIANA
}

\author{
José Henrique de Faria \\ Economista, Mestre em Administração pela UFRGS, Doutor em \\ Administração pela USP e Professor Titular da UFPR. \\ E-mail: hfaria@ceppad.ufpr.br
}

\begin{abstract}
"Quanto menos poder o sujeito tem, mais ele se atribui poder simbólico."

Maurício Tragtenberg
\end{abstract}

\section{INTRODUÇÃO}

Em abril de 1978, o professor Maurício Tragtenberg foi a Porto Alegre ministrar um curso sobre poder e sindicalismo. Sua análise da situação, tendo como objeto as greves do $\mathrm{ABC}$ paulista, compunha uma crítica sem concessões de qualquer espécie. A certa altura de sua exposição, ao avaliar as relações entre o poder e o uso de artifícios para obtê-lo, Tragtenberg propôs uma distinção, que iria aparecer em seus textos posteriores - especialmente nos que se referiam à sua crítica à delinqüência acadêmica -, entre o poder que decorria da dominação, e, portanto, das relações de autoridade e coerção, daquele que decorria do uso de símbolos e de articulações políticas. Não se tratava, para Tragtenberg, de tipos de poder, mas de instâncias de manifestação das relações.

A passagem referida no preâmbulo resume, de certa forma, uma concepção teórica que se traduziu em uma inovação na área de estudos organizacionais, não pelo fato de que ambos os conceitos eram, em si mesmos, novos, mas em função de oferecer aos pesquisadores um outro paradigma de interpretação, no qual o real e o simbólico fazem parte de uma mesma realida- de (Tragtenberg, 1991, 1999). A organização universitária, sua gestão, as relações de poder que a atravessam e a vida psíquica que se desenvolve em seu interior oferecem-se ao pesquisador como um palco para reflexões acerca de uma "economia política do poder" (Faria, 2001), que Tragtenberg soube explorar com maestria. Nesse sentido, procurando retomar as orientações tragtenberguianas, este artigo pretende analisar a relação entre administração, poder e participação no âmbito da delinquiência acadêmica, segundo a ótica do referido professor.

\section{SOBRE O PODER}

Tomando por base uma rápida revisão da literatura em seus enfoques mais significativos para o estudo do controle social nas organizações, bem como análises efetuadas sobre as relações de poder (Faria, 1985a, 1985b, 1987; Tragtenberg, 1977, 1979a, 1980b), pode-se afirmar que poder é a capacidade que possui uma classe social (ou uma de suas frações ou segmentos), uma categoria social ou um grupo (social ou politicamente organizado), de definir e realizar seus interesses objetivos específicos, mesmo contra a resistência ao exercício dessa capacidade e independentemente do nível estrutural em que tal capacidade esteja principalmente fundamentada. O exercício do poder adquire continuidade e efetividade política por ocasião do acesso do grupo ou da classe social ao 
comando das principais organizações, das estruturas institucionais ou políticas da sociedade - inclusive aquelas criadas como resultado de um processo de transformação - de maneira a pôr em prática ou a viabilizar tal exercício. Nesse sentido, o poder é uma capacidade coletiva e, como tal, deve ser adquirido, desenvolvido e mantido, inserindo-se os indivíduos em suas relações a partir de funções que desempenham no âmbito coletivo, de forma orgânica ou não, podendo influir, coordenar, liderar, representar, organizar e conferir legitimidade.

O conceito proposto diz respeito aos efeitos produzidos pelas práticas sobre a unidade das estruturas organizacionais. Esses efeitos se manifestam tanto sobre os elementos que constituem seus suportes e garantem sua coesão, com base ou não na legitimidade, quanto sobre aqueles que implicam sua reestruturação ou mesmo seu aniquilamento, pois, ainda que haja vínculos promotores de uma unidade coesa, ela é passível de rompimento parcial, total ou definitivo: um grupo não possui poder para sempre e tampouco seus interesses, estratégias e direção são sempre os mesmos. O que vai determinar a permanência e a direção são as práticas.

A capacidade de definir e realizar interesses depende das condições internas do grupo e igualmente da capacidade de outros grupos. Assim, pode-se afirmar que: a) um grupo definirá e realizará seus interesses devido às relações que se desenvolvem entre os sujeitos que o constituem - em um processo dinâmico e dialético, no qual as contradições vão dando forma a essa unidade não monolítica, pois não só os indivíduos formulam e mantêm tal capacidade quanto são determinados por ela (o que garante a coesão da unidade) -, ao mesmo tempo em que, por força das relações e das práticas de grupo ou de conflitos internos, podem reformular ou reestruturar essa capacidade - redefinindo uma nova coesão da unidade do grupo ou desagregando-o definitivamente; b) a capacidade de um grupo de definir e realizar seus interesses - condição necessária para o exercício do poder desse grupo - depende das capacidades de outros grupos de definirem e realizarem os seus, de forma que a efetividade do poder de um grupo depende diretamente da efetividade do poder de outros grupos no âmbito da determinação das práticas e nos limites fixados pelas práticas de outros grupos.

Os interesses, da maneira aqui empregada, são interesses objetivos relativamente autônomos e referem-se à sua expressão coletiva, à prática coletiva, e não à conduta ou a motivações de comportamentos dos sujeitos. O interesse individual, embalado pelo sujeito, seu papel ou posição no interior do grupo a que pertence, consiste em expectativas de ação que somente adquirem sentido quan- do tomadas pelo grupo como interesse coletivo no âmbito de suas práticas ${ }^{1}$.

Assim, o exercício do poder é a sua concretização, de maneira que o sentido do poder somente pode ser compreendido por ocasião das relações de poder, por ocasião das práticas. Desse modo, é oportuno fixar que a capacidade de definir os interesses depende de um conjunto de fatores, os quais podem ser genericamente agrupados em

\section{NÃO SE PODE FAZER DO PODER O}

\section{CENTRO DAS RELAÇÕES SOCIAIS,}

\section{POIS, DESSE MODO, AINDA QUE ELE ESTEJA EM TODA PARTE, ACABA-SE POR COLOCÁ-LO EM PARTE ALGUMA.}

quatro grandes categorias totalmente interdependentes: (I) as motivações subjetivas dos sujeitos que constituem o grupo; (II) a condição de elaboração teórica e conceitual que permita a leitura da realidade, a identificação e a análise das dificuldades, das oportunidades, riscos e estratégias de ação política; (III) a capacidade de estabelecer relações entre a própria condição de manutenção da organização e a realidade; (IV) a necessidade de preservar o caráter de identidade do grupo e a reafirmação do sentimento de pertença de seus membros.

A capacidade de realizar os interesses definidos, por seu turno, também depende de um conjunto de fatores, chamados bases ou recursos do exercício do poder. Tais bases podem ser agrupadas, essencialmente, em três dimensões ou instâncias, não excludentes, mas não necessariamente dependentes e tampouco seqüencialmente ordenadas. São elas: (I) as articulações políticas: suas estratégias e programas - ao que corresponde o desenvolvimento de competências políticas - e o conjunto simbólico-imaginário; a divulgação, por meio dos aparelhos, da ideologia - ao que correspondem toda a trama da posse, uso e disseminação de informações e o domínio do sistema de comunicação; as atitudes obscuras e ocultas que se processam à margem do sistema institucional, nos bastidores, em "segredo", que dizem respeito ao psiquismo dos sujeitos e do grupo ou aos compromissos não formalizados que visam garantir apoio político e que não podem ser manifestos na instância coletiva; (II) a autoridade legítima, tal como definida por Weber (1974); (III) a coerção (direta, indireta e sutil) - geralmente utilizada quando os demais mecanismos ou bases não lograram 
garantir a consecução dos objetivos, pois se trata de uma base politicamente muito onerosa.

O exercício do poder, quando se utiliza desses recursos da articulação política, da autoridade e da coerção, não o faz apoiado em uma única base. $O$ recurso da articulação, ainda que muitas vezes possa ser utilizado como um anteparo com relação ao emprego da autoridade legal ou da coerção, não pode prescindir totalmente de uma estrutura legal ou coercitiva que venha a garantir permanência institucional às metas perseguidas pelo grupo ou classe social. As relações de poder não são apenas resultado de práticas racionais conscientes voltadas ao interesse coletivo. De fato, não é propriamente no plano manifesto das relações que se devem procurar as motivações subjetivas, pois elas se encontram expressas tanto nas formulações quanto nas realizações, de forma que todo o aparato objetivo racional constitui um momento do processo, que é aquele da legitimação, da "publicização", do próprio manifesto. É dessa dinâmica oculto-manifesto que se definem os termos da operação dos controles sociais, ou seja, são as relações de poder que permitem operar as diversas formas de controle social nas organizações.

É preciso observar, igualmente, que o emprego de instrumentos ideológicos e ocultos de articulação política possui caráter muito próximo ao do coercitivo sutil, pois, não pertencendo à ordem da violência explícita ou recalcante, não deixa por isso de fazer uso de elementos trabalhados nos bastidores, de desejos inomináveis e de intenções que não podem ser explicitadas, bem como da manipulação na divulgação da ideologia dominante mediante aparelhos específicos, instituições e mecanismos organizacionais internos, que são do mesmo modo efetivos. É esse conjunto que Tragtenberg chamará de delinquiência e é aí que estão também todos os ordenamentos que, ainda que tomem a forma jurídica - que aparentemente poderia conferir legitimidade à ordem legal -, não têm resultado de um processo democrático. Tal problema evidencia que, do assentimento à autoridade, está se passando ao assentimento da manipulação de consciências, em que os verdadeiros poderosos não são conhecidos, pois o poder deslocou-se do visível para o invisível, do conhecido para o anônimo.

Essa análise sugere que há uma dinâmica pela qual as estruturas legais podem ser desfiguradas pelas estruturas autoritárias dando origem a uma "nova legalidade", em que a função da lei é substituída por um novo ordenamento que serve de instrumento ao exercício do poder, conferindo-lhe a aparência de legalidade e legitimidade. Isso não significa que as estruturas sejam meros instrumentos de exercício do poder. As estruturas não podem ser diretamente tomadas senão como campos em que se operam as relações sociais - essas, sim, espaços de realização das relações de poder. Se as relações de poder se desenvolvem dessa forma, isso não significa que sejam totalmente visíveis todo o tempo para todas as pessoas. É um equívoco supor que, uma vez desvendados os mecanismos do poder, já se pode enxergá-lo às claras. É certo que as relações de poder estão em toda a parte, ainda que não se pretenda reconhecê-las; que entram pelos olhos, ainda que não se queiram vê-las; que estão presentes nos discursos, ainda que não se queira falar delas.

No entanto, não se pode fazer do poder o centro das relações sociais, pois, desse modo, ainda que ele esteja em toda parte, acaba-se por colocá-lo em parte alguma. Como sugere Bourdieu (1998), "é necessário saber descobri-lo onde ele se deixa ver menos, onde ele é mais completamente ignorado, portanto, reconhecido". Por isso, é preciso compreender o caráter simbólico do poder, essa forma invisível de seu exercício que somente pode ser exercida "com a cumplicidade daqueles que não querem saber que lhe estão sujeitos ou mesmo que o exercem". É com este sentido, ou seja, é a partir da definição e da realização de interesses específicos por parte de grupos no interior das organizações acadêmicas, fundados em uma racionalidade política e em uma subjetividade psíquica, que se irá percorrer a perspectiva de Tragtenberg.

\section{DA ACADEMIA DELINQÜENTE: PODER E PARTICIPAÇÃO NA ANÁLISE TRAGTENBERGUIANA}

Maurício Tragtenberg é um pioneiro nos estudos críticos sobre poder, administração universitária e delinqüência acadêmica, oferecendo não apenas um legado, mas uma história. A teoria das organizações e a educação, no Brasil, podem ser divididas em antes e depois de Burocracia e ideologia (Tragtenberg, 1977). Crítico do autoritarismo e defensor da pedagogia libertária, Tragtenberg expõe a contradição entre a utopia que precisa ser realizada e a realidade que teima em aperfeiçoar seus mecanismos de dominação, seguindo a tradição daqueles cuja prática intelectual correspondia a enfrentamentos revolucionários (Tragtenberg, 1978,1979b,1979c,1980a,1981).

Tomando como ponto de referência a mesma linha sugerida há mais de um século e meio - em que dois jovens filósofos, Marx e Engels (1976), ao analisarem a contradição entre Estado enquanto sociedade política e sociedade civil, mostraram que, em uma democracia, seus membros, para manterem a unidade universal, não podem atribuir-se ou conquistar importância diferente daquela que lhes compete -, Tragtenberg investe contra os usurpadores, os delinqüentes, os repressores de toda a 
espécie. Em suas análises, explicita-se com clareza tanto como o exercício da democracia supõe responsabilidade política, quanto como, no cumprimento das suas atribuições, deve-se garantir a função social do universal e do particular acima de quaisquer interesses específicos. Tragtenberg, ao mostrar como o poder encontra-se incrustado nas instituições e nas organizações, indica como se dá a apropriação do saber e a perpetuação dos sistemas de dominação nos diferentes poros do tecido social.

De suas análises, pode-se deduzir um entendimento de que a prática autoritária é assumida sem crítica, de que na democracia o processo formal supera o conteúdo, de que o coletivo é um agregado de muitos singulares, e não uma unidade substancial. É nesse prisma que circulam livremente, especialmente no interior das instituições acadêmicas, ao sabor dos contextos, textos e discursos sobre democracia, participação e autoritarismo ${ }^{2}$, muitos deles defendendo a idéia de que a própria universidade é um locus privilegiado da prática democrática, uma salvaguarda da neutralidade e da defesa do conhecimento científico - tudo se dá como se a universidade fosse uma instituição homogênea, coesa, sem contradições e absolutamente desenvolvida e democrática. Ao examinar a crise da universidade, que ocorre porque a "sociedade está em crise", Tragtenberg (1979c, p. 15) percebe que, ao contrário do que afirmam alguns acadêmicos, a universidade "não é uma instituição neutra; mas sim de classe, onde as contradições aparecem. Para obscurecer estes fatores, a universidade desenvolve uma ideologia de saber neutro, científico, uma neutralidade cultural e um mito de saber 'objetivo' acima das contradições sociais".

De fato, a universidade desenvolve determinadas práticas acadêmicas e administrativas que, algumas vezes, escondem movimentos contraditórios. O processo de seleção dos membros de sua comunidade é um exemplo dessas práticas. A seleção dos alunos da graduação e da pós-graduação, caracterizada pela igualdade de oportunidade, esconde o fato de que, em cursos de alta demanda, as maiores oportunidades são conferidas aos que tiveram acesso prévio a um ensino privilegiado; a seleção dos docentes por meio de concursos, às vezes esconde a preferência das bancas pelo conteúdo teórico e político dos candidatos, quando não por relações interpessoais.

Essa situação vem reforçar o que Tragtenberg (1979c, p. 16-17) chama de "complô de belas almas", "recheadas de títulos acadêmicos, de doutorismo (...), de uma nova pedantocracia, da produção de um saber a serviço do poder, seja ele de que espécie for". Nas escolas de educação, formam-se, desse modo, tecnocratas aptos a "confeccionar reformas educacionais que, na realidade, são verdadeiras "restaurações"', da mesma forma que, em ou- tros centros educacionais, se reproduz a universidade mandarinal do século passado ao inculcar "normas de passividade, subserviência e docilidade através da repressão pedagógica". Mesmo nos "cursos críticos", a universidade dominante prevalece mediante o juízo professoral hegemônico exercido sobre os estudantes em um processo de "contaminação". "Essa apropriação da crítica pelo mandarinato universitário, mantido o sistema de exames, a conformidade ao programa e o controle da docilidade do estudante como alvos básicos, constitui-se numa farsa, numa fábrica de boa consciência para a delinqüência

\section{A SELEÇÃO DOS ALUNOS DA}

\section{GRADUAÇÃO E DA PÓS-GRADUAÇÃO,} CARACTERIZADA PELA IGUALDADE

\section{DE OPORTUNIDADE, ESCONDE O} FATO DE QUE, EM CURSOS DE

\section{ALTA DEMANDA, AS MAIORES OPORTUNIDADES SÃO CONFERIDAS} AOS QUE TIVERAM ACESSO PRÉVIO

\section{A UM ENSINO PRIVILEGIADO.}

acadêmica representada por aqueles que trocam o poder e a razão pela razão do poder."

Quando a "unidade coletiva" da universidade é ameaçada por desvios particulares ou corporativos e por críticas que revelam suas fragilidades, observa-se que a defesa do instituído diante das possibilidades de sua transformação democrática reafirma a existência de um universal totalmente aparente que, de novo, é somente a soma de infinitas particularidades, cada qual sem abdicar de seus interesses privados e encerradas em sua esfera, caracterizando o coletivo como elemento particular, essencialmente "desorgânico", em que a união se realiza apenas inconscientemente, nas costas dos indivíduos. Tal concepção do ethos singular embutido na estrutura coletiva, tomada como princípio genérico, afirma, em nome do todo, que a sociedade é apenas um conjunto de pessoas ou grupos privados, que a organização é simplesmente a soma dos seus "colaboradores" e que todos, defendendo seus interesses particulares, os transformam em coletivos, em metas e objetivos comuns. Com esse sentido, o universal torna-se não uma construção, mas uma soma; 
não um fim, mas um meio; não um valor, mas uma instância de legitimação dos agregados particulares.

Se cada circunstância pudesse reivindicar uma verdade, nenhum código seria produzido, nenhuma sociedade seria organizada e nada seria instituído. Isso não significa que, uma vez definidas, as verdades, assim como os princípios de conduta, se tornem imutáveis. De fato, como analisa Engels (1979) em sua crítica ao Senhor Düring, se o produto do exercício do pensamento pudesse reivindicar a validez soberana das verdades, a sociedade alcançaria um nível tal que se teria esgotado a infinidade do mundo intelectual. Se tudo já estivesse pronto, nada mais haveria a produzir. Se tudo já se soubesse, nada mais haveria a investigar. Entretanto, é interessante verificar que, mesmo em situações que se caracterizam pela renovada produção intelectual e pela permanente investigação, também acabem emergindo esses axiomas, definitivos e inapeláveis, dos quais se extraem as deduções da existência humana, do poder ser e do dever ser.

E é importante observar que é justamente aí que alguns membros das organizações acadêmicas asseguram, em seus discursos, que só a sua concepção é aceitável, que tudo o mais é equívoco e, como profetas recém-saídos do forno, trazem em sua mochila, pronta para ser posta em circulação, a única verdade e a eterna justiça. A relação professor-aluno é sempre uma relação de poder quando tem como suporte os aparatos da coerção institucionalizada e o domínio de um saber inacessível. Tragtenberg (1979c, p.18) observa bem essas práticas, indicando que "o mestre possui um saber inacabado e o aluno uma ignorância transitória: não há saber absoluto, nem ignorância absoluta. A relação de saber não institui a diferença entre aluno e professor: a separação entre aluno e professor opera-se através de uma relação de poder simbolizada".

A vida cotidiana nas academias passa a ser, assim, preenchida por vários espaços em que o falso toma a forma do verdadeiro, instituindo um pacto no qual ali tudo é aceito como norma, como próprio da natureza, de maneira que as verdades impostas e a ética conceituada não venham a provocar, nos sujeitos, incômodo, envolvimento ou dor. Os grupos e alguns de seus líderes, visando manter uma unidade competitiva na luta pelo poder, desfilam um conjunto de regras, de comportamentos e de condutas administrativas e morais, a partir do qual julgarão outros grupos ou seus membros mais destacados. Entretanto, o que deveria ser princípio e compromisso, não passa de discurso. Na medida em que aquilo, antes definido como ético ou democrático, venha a se constituir em obstáculo ao exercício ou à luta pelo poder, toda a lógica passa a ser reconstruída, de maneira a abarcar as novas regras, atitu- des ou comportamentos agora necessários e, portanto, aceitos. Tais alterações não se processam, destarte, apenas pela dinâmica das relações, pela dialética da natureza, mas por interesses particulares. Como bem aponta Tragtenberg (1979c, p. 19), "em nome do 'atendimento à comunidade' e em nome do 'serviço público', a universidade tende cada vez mais à adaptação indiscriminada a quaisquer pesquisas a serviço dos interesses econômicos hegemônicos". "A escolha das pesquisas depende dos financiamentos possíveis; por outro lado, a 'moda' acadêmica impõe sua tirania. Uma pesquisa é determinada não porque se é obrigado a ter essa ou aquela orientação teórica para receber financiamento, mas recebe financiamento por ter essa ou aquela orientação teórica. Tratase de uma determinação que opera com alto nível de sutileza" (Tragtenberg, 1979c, p. 30).

Assim, os princípios que guiam esses filantropos da intelectualidade no interior das academias aparecem sem estilo e sem densidade política, porque resolvem suas carências com frases tradicionais e com bordões; sem conteúdo, porque, sendo vazios de teoria, preenchem suas falas com estéticas duvidosas; sem horizonte, porque sua visão de mundo não ultrapassa a porta da sala de reuniões, e sem compromissos, porque legitimam práticas organizacionais com superficialidade e, às vezes, com a profundidade da banalização. São princípios nos quais não cabe a sabedoria e nos quais o sujeito não vale pelo afeto que cultiva, mas pela esperteza capaz de lhe conferir vantagens competitivas. A introdução do ensino pago nas universidades públicas, a realização de quaisquer cursos a qualquer clientela que por eles se disponha a pagar, as atividades de prestação de serviços em que o que mais importa são os recursos, e não a qualidade acadêmica oferecida e resultante dos serviços, o financiamento da pesquisa por organizações de interesses privados, a realização de encontros em que se operam vendas de conhecimento científico ou em que se constroem palcos nos quais os pares se apresentam para sua autopromoção, estas se constituem em graves ameaças ao ensino público libertário na perspectiva tragtenberguiana.

Tragtenberg (1979c, p. 20-22), de fato, percebe criticamente esse movimento que atualmente ganha contornos cada vez mais definidos. Sobre sua ética e sua função social, afirma que "uma universidade que produz pesquisas ou cursos a quem é apto a pagá-las perde o senso de discriminação ética e da finalidade social de sua produção: é uma 'multiversidade', que se vende no mercado ao primeiro comprador, sem averiguar o fim da encomenda, acobertada pela ideologia da neutralidade do conhecimento e seu produto".

Sobre as avaliações de desempenho, sugere que "a 
política das 'panelas' acadêmicas de corredor universitário e a publicação a qualquer preço de um texto qualquer constituem-se no metro para medir o sucesso universitário". Sobre as valorizações simbólicas, observa que "a maioria dos congressos acadêmicos universitários serve como 'mercado humano', onde entram em contacto pessoas e cargos acadêmicos a serem preenchidos", pois o "mundo da realidade concreta é sempre muito generoso com o acadêmico" na medida em que o título conferido pela academia torna-se "o passaporte que permite o (seu) ingresso nos escalões superiores da sociedade", o que reforça o problema da desvinculação da universidade com os processos de transformação social e a tese de que "a ideologia do acadêmico é não ter nenhuma ideologia: faz fé de apolítico, isto é, serve à política do poder". "Cobertos pelo ideal de 'neutralidade ante valores', a maioria dos acadêmicos universitários vegetam no conforto intelectual, agasalhados pelas sinecuras burocráticas e legitimados ideologicamente pelo apoliticismo: a ideologia dos que não têm ideologia. Na verdade, esse apoliticismo converte-se na ideologia da cumplicidade trustificada. Sem dúvida, o cultivo de ideologia livre de valores é paralelo à despreocupação sobre as implicações éticas e políticas do conhecimento"(Tragtenberg, 1979c, p. 28).

As dimensões da ética e da democracia, que todos os membros da universidade defendem em público, nem sempre possuem a mesma consistência na prática privada dos grupos ou dos indivíduos. As interpretações produzidas nos princípios formulados por esses membros da intelectualidade acadêmica, independentemente do lugar que ocupem na estrutura formal - por estarem voltadas aos seus interesses específicos, aos seus objetivos e à sua concepção de mundo -, pretendem se constituir em uma panacéia que, aplicada em qualquer condição, impõem, como sendo fruto maduro do pensamento soberano, um mero encadeamento de frases com muito mais que um (e, em alguns casos, sem nenhum) sentido. Esse tipo de prática, muito adequada a impactos momentâneos, na realidade, não é senão uma nova versão do velho e favorito método apriorístico, que consiste em estabelecer e provar propriedades de um objeto partindo não dele mesmo mas do conceito que dele antes se formou. Assim, não é o conceito que se ajusta ao objeto mas este que se ajusta àquele (Engels, 1979), segundo uma lógica previamente definida, na qual os conceitos de democracia e ética acadêmica cabem onde se deseja pô-los antes até de os construir: a realidade é deduzida não de si mesma, mas da idéia, por isso não é senão ideologia.

Um exemplo (Faria, 2000) é a crítica que certos círculos progressistas fazem à adoção de critérios em processos de avaliação institucional em instituições públicas de ensino, os quais revelam fragilidades que, para eles, seria melhor que permanecessem escondidas. Esses círculos interpretam o movimento dialético da vida coletiva como um simples avanço da competitividade capitalista no espaço público, tomando este como se fosse o altar da justiça social, e não a sua coxia. Assim, defendem a ausência de critérios e de atitudes não porque estes sejam impróprios, mas para esconder suas segundas intenções, para abrir espaço de manobra política às suas velhas e surradas práticas de distribuição de favores, totalmente incompatíveis com qualquer projeto democrático. Os discursos, coberturas que sustentam essa tese, contudo, parecem, ao público, ter saído dos mais puros manuais de democracia política.

\section{AS DIMENSÕES DA ÉTICA E DA DEMOCRACIA, QUE TODOS OS} MEMBROS DA UNIVERSIDADE
DEFENDEM EM PÚBLICO, NEM

SEMPRE POSSUEM A MESMA CONSISTÊNCIA NA PRÁTICA PRIVADA
DOS GRUPOS OU DOS INDIVÍDUOS.

Tragtenberg (1979c, p. 22-23) assegura que "a valorização do que seja um homem culto está estritamente vinculada a seu valor na defesa de valores de cidadania essenciais, ao seu exemplo revelado não pelo seu discurso, mas por sua existência e ação". Para que a universidade possa participar do desenvolvimento desse sujeito, Tragtenberg acredita que "a alternativa é a criação de canais de participação real de professores, estudantes e funcionários no meio universitário que se oponham à esclerose burocrática da instituição. A autogestão pedagógica teria o mérito de devolver à universidade um sentido de existência". Observa, finalmente, que "a participação discente não se constitui num remédio mágico aos males (...) apontados, porém a experiência demonstrou que a simples presença discente em colegiados é fator de sua moralização". Porém, essa crença exposta por Tragtenberg nos canais de participação real, com a qual se pode concordar em tese, tem se mostrado, concretamente, um engodo. Os canais de participação real existem, a participação discente é assegurada, mas a democracia, a ética e a justiça não são garantidas por esses dispositivos.

Se forem superadas as dificuldades de organização dos 
professores, funcionários e estudantes, se for superada a falta de motivação, de participação política e de valorização das representações, ainda restará vencer a máquina trituradora da burocracia pública, o conservadorismo obscurantista da academia, as práticas destrutivas e intestinas de poder que não se manifestam nos canais de participação, mas nos bastidores, a preservação das corporações de ofício e de suas práticas instaladas na academia, a mediocridade dos processos de avaliação da produção acadêmica.

Até que ponto a motivação participativa pode valorizar os fins para definir os meios, transformar os problemas técnicos em problemas também políticos, preferir a consulta pública a soluções de gabinete, substituir a indignidade intelectual pela dignidade da inteligência? A simples existência de mecanismos formais de participação não garante a plena prática da democracia. A máquina burocrática, os jogos de interesses, a mídia oficial que permite ao MEC desqualificar suas próprias universidades, a falta de uma política pública verdadeiramente comprometida com a educação, a diminuição dos recursos e o sucateamento das instituições públicas de ensino, os vícios corporativos, as práticas pedagógicas coercitivas ("bancárias", diria Paulo Freire), a vinculação de pesquisas a interesses particulares, a individualização da produção do conhecimento, tudo isso contribui, sem dúvida, para a reprodução da injustiça, do autoritarismo, da despolitização intelectual e do conservadorismo.

Mas é ainda no interior desse ambiente desfavorável que se produzem as melhores pesquisas, que se faz a melhor extensão, que se pratica o melhor ensino, que se pode democratizar o acesso ao conhecimento, que as críticas podem ser formuladas, que a autonomia intelectual pode ser exercitada, enfim, que se pode encontrar uma produção intelectual libertária como a do professor Maurício Tragtenberg. $\bigcirc$

\section{REFERÊNCIAS BIBLIOGRÁFICAS}

BOURDIEU, Pierre. O poder simbólico. Rio de Janeiro : Bertrand Brasil, 1998.

ENGELS, Friederich. Anti-Düring. 2. ed. São Paulo : Paz e Terra, 1979

FARIA, José Henrique de. Relações de poder e formas de gestão. Curitiba : Criar, 1985a.

FARIA, José Henrique de. Autoritarismo nas organizações. Curitiba : Criar, 1985b

FARIA, José Henrique de. Comissões de fábrica: poder e trabalho nas unidades produtivas. Curitiba : Criar, 1987.

FARIA, José Henrique de. Tecnologia e processo de trabalho. Curitiba : Editora da UFPR, 1992.

FARIA, José Henrique de. Ética moral e democracia: os paradoxos da práxis organizacional. Curitiba : ENEO, 2000.

FARIA, José Henrique de. Economia política do poder. Curitiba : UFPR, 2001. Paper.
MARX, Karl, ENGELS, Friederich. A ideologia alemã. 3. ed. Lisboa : Presença, 1976.

TRAGTENBERG, Maurício. Burocracia e ideologia. São Paulo : Ática, 1977.

TRAGTENBERG, Maurício. Francisco Ferrer e a pedagogia libertária. Educação \& Sociedade, São Paulo, v. 1, n. 1, p. 17-49, set. 1978 .

TRAGTENBERG, Maurício. Violência e trabalho através da imprensa sindical. Educação \& Sociedade, São Paulo, v. 1, n. 2, p. 87-120, jan. 1979a.

TRAGTENBERG, Maurício. A delinqüência acadêmica. Educação \& Sociedade, São Paulo, v. 1, n. 3, p. 76-82, maio $1979 b$.

TRAGTENBERG, Maurício. A delinqüência acadêmica: o poder sem saber e o saber sem poder. São Paulo : Rumo, 1979c.
TRAGTENBERG, Maurício. 0 conhecimento expropriado e reapropriado pela classe operária: Espanha 80 . Educação \& Sociedade, São Paulo, v. 2, n. 7, p. 53-62, set. 1980a.

TRAGTENBERG, Maurício. Administração, poder e ideologia. São Paulo : Moraes, 1980b.

TRAGTENBERG, Maurício. Educação e política: proposta integralista. Educação \& Sociedade, São Paulo, v. 3, n. 8, p. 97-110, mar. 1981.

TRAGTENBERG, Maurício. Memorial - Maurício Tragtenberg. Pro-Posições, Campinas, v. 4, p. 79-87, mar. 1991. Revista quadrimestral da Faculdade de Educação da Unicamp.

TRAGTENBERG, Maurício. Memórias de um autodidata no Brasil. Organizada por Sonia Alem Marrach. São Paulo : Escuta, 1999.

WEBER, Max. Economia y sociedad: esbozo de sociología compreensiva. México : Fondo de Cultura Económica, 1974. 2 v.
NOTAS

1. Nenhum indivíduo, no grupo, expressa seu interesse como sendo propriamente seu. Os indivíduos formulam seus interesses a partir de um discurso coletivo, tentando traduzir seu desejo no desejo do grupo, em busca de uma legitimidade e de uma impessoalidade que venham a garantir que seu interesse seja adotado pelo grupo como sendo interesse do grupo, seja em sua formulação original, proposta pelo indivíduo, seja em uma formulação reconstruída. Não raro, quando interesses conflitantes são expostos, o grupo é levado a decidir a alternativa que melhor convém, com todas as implicações daí decorrentes (Faria, 2000).

2. Estas concepções invadiram a literatura organizacional sob a forma de defesa de modelos de "Gestão Participativa", em que a participação assume o mesmo significado que democracia. Para uma crítica a esses "modelos", ver Tragtenberg (1980b) e Faria (1987, 1992).

3. 0 que dizer, então, a propósito, do Exame Nacional de Cursos (o "Provão"), instituído pelo MEC para avaliar os cursos e as universidades? 